\title{
ANÁLISE DA MORFOMETRIA E DO USO E COBERTURA DA TERRA DA MICROBACIA DO CÓRREGO IPANEMINHA DE BAIXO, SOROCABA, SP
}

\author{
Mariana Santos Leal ${ }^{1 *}$, Kelly Cristina Tonello ${ }^{2}$ \\ 1* Universidade Federal de São Carlos, Programa de Pós-Graduação em Planejamento e Uso de Recursos Renováveis, Sorocaba, São Paulo, \\ Brasil - mari_floresta@hotmail.com \\ ${ }^{2}$ Universidade Federal de São Carlos, Departamento de Ciências Ambientais, Sorocaba, São Paulo, Brasil - kellytonello@ufscar.br
}

Recebido para publicação: 18/03/2016 - Aceito para publicação: 28/09/2016

\begin{abstract}
Resumo
A bacia hidrográfica é considerada uma unidade de planejamento e gestão tornando-se importante o conhecimento de suas características, tanto físicas quanto de uso e cobertura da terra, uma vez que estas influenciam sua dinâmica hidrológica. Deste modo, este trabalho teve por objetivo a caracterização da morfometria e do uso e cobertura da terra da microbacia do córrego Ipaneminha de Baixo em Sorocaba, SP. A morfometria foi realizada por meio de parâmetros geométricos, de relevo e drenagem enquanto que o uso e cobertura da terra foram obtidos através de interpretação visual de uma imagem digital orbital e vetorização em tela das classes, sendo que ambas as análises foram realizadas em um Sistema de Informação Geográfica. De acordo com a morfometria da microbacia pôde-se perceber que ela apresenta características físicas favoráveis à conservação da água, no entanto as áreas de preservação permanente encontraram-se com déficit de vegetação nativa em relação ao estabelecido por legislação. A microbacia está sendo ocupada predominantemente por plantio de citrus, culturas temporárias e pastagem, porém a vegetação nativa também está presente na forma de fragmentos dispersos.

Palavras-chave: Processos hidrológicos; área de preservação permanente; geomorfologia.
\end{abstract}

\begin{abstract}
Morphometry and land use and cover analysis of Ipaneminha de Baixo watershed, Sorocaba, SP. A watershed is considered a planning and management unit, consequently it is important to know their characteristics, both physical and use and land cover, as these influence their dynamic hydrological. Thus, this study aimed to characterize the morphometry and the use and land cover of the Ipaneminha de Baixo watershed in Sorocaba, SP. For the morphometric evaluation were considered geometric, relief and drainage parameters, while the use and land cover was obtained through visual interpretation of an orbital digital image and vectorization screen of classes, and both analyzes were performed in a Geographic Information System. According to morphometry could be seen that the watershed presents physical characteristics favorable for the water conservation, however the permanent preservation areas have a native vegetation deficit. The watershed has been occupied predominantly by citrus plantations, temporary crops and pasture, but the native vegetation is also present as fragments.

Keywords: Hydrological processes; permanent preservation area; geomorphology.
\end{abstract}

\section{INTRODUÇÃO}

Uma bacia hidrográfica, limitada pelo divisor de águas ou divisor topográfico, abrange toda a área de captação natural da água da chuva e proporciona escoamento superficial para o canal principal e seus tributários (LIMA, 2008). De acordo com a Lei Federal n ${ }^{\circ} .9 .433$ de 1997, a bacia hidrográfica deve ser considerada a unidade de planejamento e gestão de Recursos Hídricos. Sendo assim, é importante conhecer as suas características, tanto físicas quanto de uso e cobertura do solo, que influenciam a sua dinâmica hidrológica.

O deflúvio, infiltração, escoamento superficial e evapotranspiração são, por exemplo, alguns processos influenciados pelas características físicas e biológicas da bacia hidrográfica (TONELLO et al., 2006) Fatores como cobertura vegetal, geologia, topografia, clima e principalmente o manejo de solo influenciam diretamente a qualidade e quantidade de água na bacia (ARCOVA et al., 1998), que também podem ser alteradas pelo desmatamento, uso indiscriminado de agroquímicos ou excessiva exploração dos recursos naturais (PINTO et al., 2004).

As características físicas, especialmente aquelas associadas ao relevo, à forma e à rede de drenagem, estão altamente relacionadas ao tempo e velocidade de escoamento da água, o que vai incidir em maior ou menor infiltração da água no solo. De acordo com a descrição física da bacia é possível saber qual a suscetibilidade da mesma quanto ao risco de cheia, escoamento superficial e processos erosivos, dando uma indicação de como deve ser o manejo da bacia para que ela possa proporcionar maior infiltração da água no solo. 
Para que a bacia funcione como um ambiente permeável, onde a água infiltre e percole até o lençol freático, o solo deve estar corretamente ocupado de acordo com as características de cada sítio. Assim, a bacia é capaz de captar a água das chuvas, armazená-la e cedê-la aos poucos por meio das nascentes durante todo o ano.

Por sua vez, as informações obtidas a partir de um diagnóstico sobre o uso e cobertura do solo, principalmente nas Áreas de Preservação Permanente (APPs), são úteis para nortear as ações de manejo da bacia, pois a partir delas é possível verificar como a bacia está sendo manejada e sua possível consequência na produção de água.

A ocupação das APPs pela agropecuária e expansão urbana é crescente e tem causado intensa degradação ambiental (FREITAS et al., 2013). A proteção dessas áreas está estabelecida na Lei Federal $n^{\circ}$. 12.651/12 devido à extrema importância que apresentam. Elas atuam na facilitação da infiltração de água no solo e do abastecimento do lençol freático, na manutenção da qualidade e quantidade da água e podem servir como obstáculo ao escoamento superficial de partículas e sedimentos, que por sua vez, causam poluição e assoreamento dos recursos hídricos (LIMA; ZAKIA, 2004).

Dessa forma, o objetivo desse trabalho foi caracterizar a morfometria da microbacia hidrográfica do córrego Ipaneminha de Baixo, assim como do uso e cobertura da terra, principalmente nas áreas de preservação permanente, de forma a subsidiar ações que promovam o seu adequado manejo e a conservação da água.

\section{MATERIAL E MÉTODOS}

A microbacia do Córrego Ipaneminha de Baixo está localizada no município de Sorocaba, SP, sendo contribuinte do Rio Ipanema, integrante do sistema de abastecimento da bacia hidrográfica do Rio Sorocaba. A área de estudo está entre as coordenadas $23^{\circ} 32^{\prime}-23^{\circ} 34^{\prime} \mathrm{S}$ e $47^{\circ} 31^{\prime}-47^{\circ} 30^{\prime} \mathrm{W}$.

O município de Sorocaba está localizado no interior de São Paulo a 90 quilômetros da capital. Com uma área de, aproximadamente, $456 \mathrm{Km}^{2}$ e população de 644.919 habitantes (IBGE, 2016), o município enfrenta um rápido crescimento demográfico, o que exige do poder público cuidados e gestão equilibrada para manutenção da qualidade de vida à população.

Sorocaba é caracterizada como área de tensão ecológica, onde originalmente encontra-se a Floresta Ombrófila Densa e Mista, Floresta Estacional Semidecidual e Cerrado. De acordo com Köppen, o clima da região é classificado como Cwa (temperado seco e quente com verão quente), com temperatura anual média de $22,1^{\circ} \mathrm{C}$. A altitude média é de $580 \mathrm{~m}$ e a precipitação anual é de 1311,2 mm (CEPAGRI, 2015).

A região está localizada na transição do Planalto Atlântico para a Bacia Sedimentar do Paraná, no início da unidade geomorfológica conhecida como Depressão Periférica Paulista, sendo, portanto situada em rebordo de maciço antigo. O relevo é composto por litologias sedimentares paleozóicas de arenitos e siltitos e formas mais rugosas ligadas ao embasamento cristalino como corpos graníticos e quartzíticos (VILLELA, 2011).

Quanto às classes de solo, as de Argissolos e Latossolos predominam, embora ocorra também Cambissolos, Neossolos litólicos e Gleissolos em algumas porções do município (OLIVEIRA et al, 1999).

Para a análise morfométrica foi utilizada uma carta planialtimétrica do Instituto Geográfico e Cartográfico do Estado de São Paulo (IGC) na escala 1:10.000, folha SF-23-Y-C-IV-2-NE-D, Fazenda São Marcos. Toda a base de dados e os parâmetros morfométricos (Tabela 1) foram analisados no programa ArcMap 10.1.

Tabela 1. Parâmetros morfométricos e seus respectivos métodos de obtenção.

Table 1. Morphometric parameters and their methods of obtaining.

\begin{tabular}{|c|c|c|}
\hline Parâmetro morfométrico & Método & Referência \\
\hline Índice de sinuosidade (Is) & $\begin{array}{l}\text { Is }=\mathrm{L} / \mathrm{dv} \text {, onde L é o comprimento do curso d'água principal } \\
(\mathrm{km}) \text { e dv é a distância vetorial do canal principal }(\mathrm{km})\end{array}$ & Horton (1945) \\
\hline Fator de forma (Kf) & $\begin{array}{l}\mathrm{Kf}=\mathrm{A} / \mathrm{Le}^{2}, \text { onde A é a área da bacia }\left(\mathrm{km}^{2}\right) \text { e Le é o } \\
\text { comprimento do eixo da bacia }(\mathrm{km})\end{array}$ & Horton (1932) \\
\hline Coeficiente de compacidade (Kc) & $\begin{array}{l}\mathrm{Kc}=0,28 * \mathrm{P} / \sqrt{\mathrm{A}} \text {, onde } \mathrm{P} \text { é o perímetro da bacia }(\mathrm{km}) \text { e A é a } \\
\text { área da bacia }\left(\mathrm{km}^{2}\right)\end{array}$ & Vilela e Matos (1975) \\
\hline Índice de circularidade (Ic) & $\begin{array}{l}\mathrm{Ic}=12,57 * \mathrm{~A} / \mathrm{P}^{2}, \text { onde } \mathrm{A} \text { é a área da bacia }\left(\mathrm{km}^{2}\right) \text { e P é o } \\
\text { perímetro da bacia }(\mathrm{km})\end{array}$ & Strahler (1964) \\
\hline Padrão de drenagem & $\begin{array}{l}\text { Classificação feita com base em critérios geométricos: } \\
\text { Dendrítico, treliça, retangular, paralelo, radial e anelar }\end{array}$ & Horton (1945) \\
\hline Amplitude altimétrica $(\Delta \mathrm{a})$ & $\begin{array}{l}\Delta \mathrm{a}=\mathrm{H}-\mathrm{h} \text {, onde } \mathrm{H} \text { é altitude máxima (m) e h altitude mínima } \\
(\mathrm{m})\end{array}$ & Lima (2008) \\
\hline Declividade & $\begin{array}{l}\text { Obtida através do modelo numérico do terreno em ambiente } \\
\text { de Sistema de Informação Geográfica }\end{array}$ & $\begin{array}{l}\text { Menezes et al. (2014) } \\
\text { Embrapa (1979) }\end{array}$ \\
\hline Orientação da bacia & $\begin{array}{l}\text { É definida de acordo com a face de exposição da foz da bacia } \\
\text { a umas dessas possíveis direções: Norte }\left(0-360^{\circ}\right) \text {, Nordeste } \\
\left(45^{\circ}\right) \text {, Leste }\left(90^{\circ}\right) \text {, Sudeste }\left(135^{\circ}\right) \text {, Sul }\left(180^{\circ}\right) \text {, Sudoeste } \\
\left(215^{\circ}\right) \text {, Oeste }\left(270^{\circ}\right) \text { e Noroeste }\left(315^{\circ}\right)\end{array}$ & Tonello (2006) \\
\hline Razão de relevo (Rr) & $\begin{array}{l}\mathrm{Rr}=\Delta \mathrm{a} / \mathrm{L} \text {, onde } \Delta \mathrm{a} \text { é a amplitude altimétrica }(\mathrm{km}) \text { e } \mathrm{L} \text { é o } \\
\text { comprimento do curso d'água principal }(\mathrm{km})\end{array}$ & Schumm (1956) \\
\hline
\end{tabular}




\begin{tabular}{|c|c|c|}
\hline Ordem do curso d’água & $\begin{array}{l}\text { Cursos d'água com apenas um segmento são considerados de } \\
1^{\mathrm{a}} \text { ordem. A junção de dois segmentos de } 1^{\mathrm{a}} \text { ordem gera um } \\
\text { segmento de } 2^{\mathrm{a}} \text { ordem e assim sucessivamente }\end{array}$ & Strahler (1957) \\
\hline Gradiente do canal principal (Gc) & $\begin{array}{l}\mathrm{Gc}=\mathrm{H} / \mathrm{L} * 100 \text {, onde } \mathrm{H} \text { é altitude máxima }(\mathrm{km}) \text { e L é o } \\
\text { comprimento do curso d'água principal }(\mathrm{km})\end{array}$ & Horton (1945) \\
\hline Densidade de drenagem (Dd) & $\begin{array}{l}\mathrm{Dd}=\mathrm{Lt} / \mathrm{A} \text {, onde Lt é comprimento total dos cursos d'água } \\
(\mathrm{km}) \text { e A é a área da bacia }\left(\mathrm{km}^{2}\right)\end{array}$ & Horton (1932) \\
\hline Densidade hidrográfica (Dh) & $\begin{array}{l}\mathrm{Dh}=\mathrm{n} / \mathrm{A} \text {, onde n é o número de cursos d'água e } \mathrm{A} \text { é a área } \\
\text { da bacia }\left(\mathrm{km}^{2}\right)\end{array}$ & Horton (1945) \\
\hline Coeficiente de manutenção $(\mathrm{Cm})$ & $\mathrm{Cm}=1 / \mathrm{Dd}$, onde Dd é a densidade de drenagem & Schumm (1956) \\
\hline Extensão do percurso superficial & Eps $=1 / 2 * \mathrm{Dd}$, onde Dd é a densidade de drenagem & Horton (1945) \\
\hline
\end{tabular}

Para a análise do uso e cobertura da terra foi utilizada uma imagem digital Rapideye do ano de 2013 (MMA, 2015).

A delimitação das classes foi obtida por meio de vetorização em tela, no programa ArcMap 10.1, após a interpretação visual do uso e cobertura. As classes identificadas foram as seguintes: vegetação nativa, corpo d'água, estradas, rodovia, citrus, malha urbana, área edificada, pastagem, cultura temporária, área úmida, pinus e loteamento (IBGE, 2013).

Antes de se verificar o uso e cobertura nas áreas de preservação permanente foi criado um buffer seguindo a Lei Federal $\mathrm{n}^{\circ}$. 12.651/12, onde a APP ao redor das nascentes teve um raio de 50 metros e largura de $50 \mathrm{~m}$ ao redor das acumulações naturais ou artificiais de água com mais de 1 ha enquanto que nas margens dos cursos d'água ela apresentou largura de 30 metros.

Cabe ressaltar que caso haja áreas com uso consolidado nas APPs nos imóveis rurais de até quatro módulos fiscais, a faixa a ser restaurada será menor, variando de acordo com o tamanho da propriedade, sendo que no município de Sorocaba um módulo fiscal corresponde a 12 hectares (INCRA, 2013).

\section{RESULTADOS}

\section{Morfometria}

A área de estudo (Figura 1) apresentou padrão de drenagem dendrítico e grau de ramificação de $3^{\mathrm{a}}$. ordem.

A partir do cálculo da área (A) e do perímetro (P) da microbacia, do comprimento dos cursos d'água (Lt) e do eixo da microbacia (Le) foi possível obter os demais parâmetros morfométricos, apresentados na tabela 2.

A microbacia apresentou um índice de sinuosidade de 1,07; um indicador que infere sobre o quão retilíneo ou sinuoso é o curso d'água principal.

A análise da forma da bacia dependeu dos parâmetros: índice de circularidade, que neste caso foi de 0,63; fator de forma que foi de 0,34 e coeficiente de compacidade que foi de 1,25. Portanto, ao analisar-se conjuntamente esses parâmetros chegou-se a conclusão que a microbacia apresenta forma oblonga/ovalada segundo classificação sugerida por Nardini et al. (2013).

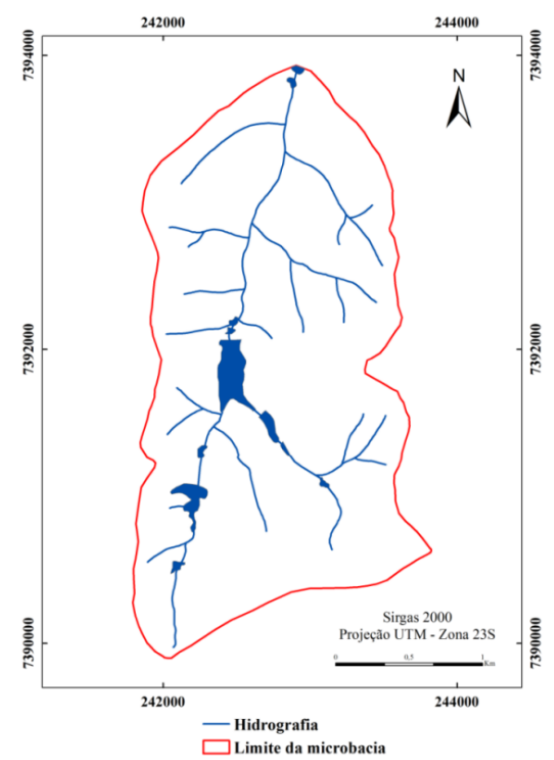

Figura 1. Microbacia Ipaneminha de Baixo, Sorocaba, SP.

Figure 1. Ipaneminha de Baixo watershed, Sorocaba, SP.

FLORESTA, Curitiba, PR, v. 46, n. 4, p. 439 - 446, out. / dez. 2016.

Leal, M. S.; Tonello, K. C.

ISSN eletrônico 1982-4688

DOI: $10.5380 /$ rf.v46i3.45809 
Tabela 2. Características morfométricas da microbacia Ipaneminha de Baixo, Sorocaba, SP.

Table 2. Morphometric characteristics of the Ipaneminha de Baixo watershed, Sorocaba, SP.

\begin{tabular}{|c|c|c|c|}
\hline & Parâmetro morfométrico & & Valor \\
\hline \multirow{8}{*}{ 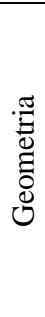 } & Área & $\mathrm{A}$ & $5,77 \mathrm{~km}^{2}$ \\
\hline & Perímetro & $\mathrm{P}$ & $10,70 \mathrm{~km}$ \\
\hline & Comprimento do eixo da bacia & Le & $4,120 \mathrm{~km}$ \\
\hline & Índice de sinuosidade & Is & 1,07 \\
\hline & Fator de forma & $\mathrm{Kf}$ & 0,34 \\
\hline & Coeficiente de compacidade & $\mathrm{Kc}$ & 1,25 \\
\hline & Índice de circularidade & Ic & 0,63 \\
\hline & Padrão de drenagem & - & Dendrítico \\
\hline \multirow{9}{*}{$\frac{\stackrel{\partial}{d}}{\mathscr{Q}}$} & Altitude mínima & $\mathrm{h}$ & $580 \mathrm{~m}$ \\
\hline & Altitude média & $\mathrm{Hm}$ & $624 \mathrm{~m}$ \\
\hline & Altitude máxima & $\mathrm{H}$ & $668 \mathrm{~m}$ \\
\hline & Amplitude altimétrica & - & $88 \mathrm{~m}$ \\
\hline & Declividade mínima & - & $0,068 \%$ \\
\hline & Declividade média & $\mathrm{Dm}$ & $8,45 \%$ \\
\hline & Declividade máxima & - & $30,21 \%$ \\
\hline & Orientação & - & Norte \\
\hline & Razão de relevo & $\mathrm{Rr}$ & 0,02 \\
\hline \multirow{9}{*}{ 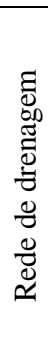 } & Ordem da bacia & - & $3^{\mathrm{a}}$ \\
\hline & Número de canais & $\mathrm{n}$ & 18 \\
\hline & Gradiente do canal principal & Gc & $15,6 \%$ \\
\hline & Densidade de drenagem & Dd & $2,60 \mathrm{~km} / \mathrm{km}^{2}$ \\
\hline & Densidade hidrográfica & Dh & 3,82 canais $/ \mathrm{km}^{2}$ \\
\hline & Coeficiente de manutenção & $\mathrm{Cm}$ & $0,38 \mathrm{~km}^{2} / \mathrm{km}$ \\
\hline & Extensão do percurso superficial & Eps & $1,3 \mathrm{~km}$ \\
\hline & Comprimento do curso d'água principal & $\mathrm{L}$ & $4,282 \mathrm{~km}$ \\
\hline & Comprimento total dos cursos d'água & $\mathrm{Lt}$ & $14,934 \mathrm{~km}$ \\
\hline
\end{tabular}

Com relação às características de relevo a microbacia apresentou declividade média de $8,5 \%$, sendo caracterizada com relevo predominantemente ondulado, onde 12,3\% do terreno foram classificados como plano; $35,8 \%$ suave ondulado; $50,6 \%$ ondulado; $1,3 \%$ forte ondulado. A altitude variou de 580 a 668 metros resultando em altitude média de $624 \mathrm{~m}$ e amplitude altimétrica de 88 metros. A face de exposição da foz da microbacia foi à orientação norte.

A razão de relevo que pode ser classificada em baixa (0 a 0,1$)$, média $(0,11$ a 0,30$)$ e alta $(0,31$ a 0,60$)$, neste caso $(0,02)$ foi considerada baixa. O gradiente do canal principal foi de $15,6 \%$, apontando uma baixa declividade do curso d'água principal.

A densidade de drenagem, $2,60 \mathrm{~km} / \mathrm{km}^{2}$, pode ser considerada como média, pois segundo Villela e Mattos (1975) o valor deste parâmetro varia de $0,5 \mathrm{Km} / \mathrm{Km}^{2}$, em bacias com baixa drenagem, a 3,5 ou mais, nas bacias excepcionalmente bem drenadas.

A densidade hidrográfica foi de 3,82 canais $/ \mathrm{km}^{2}$ e de acordo com o coeficiente de manutenção obtido é preciso no mínimo $0,38 \mathrm{~km}^{2}$ para manter um quilômetro de curso d'água.

A extensão do percurso superficial, que representa a distância média percorrida pela água da chuva antes de encontrar um curso d'água, foi de $1,3 \mathrm{~km}$.

\section{Uso e cobertura da terra}

Em termos de ocupação da terra, há predominância na microbacia de citrus e culturas temporárias e, que juntas totalizam cerca de $40 \%$ da área, enquanto que as pastagens estão presentes em aproximadamente $20 \%$ da área total (Figura 2, Tabela 3). A cobertura do solo por vegetação nativa é de 116,89 ha, o que representa $20 \%$ da área de estudo. Na microbacia também se encontra um loteamento de 45,99 ha e uma malha urbana de 15,59 ha.

As áreas de preservação permanente dos corpos d'água contabilizam cerca de 100 ha e estão sendo principalmente ocupadas por vegetação nativa, seguida de citrus, pastagem e cultura temporária. 


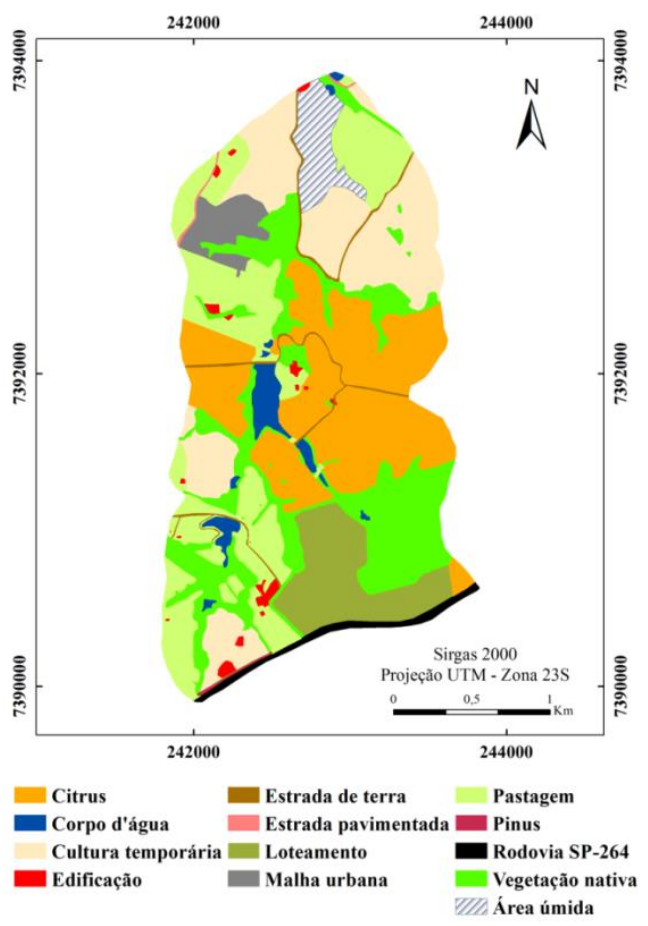

(a)

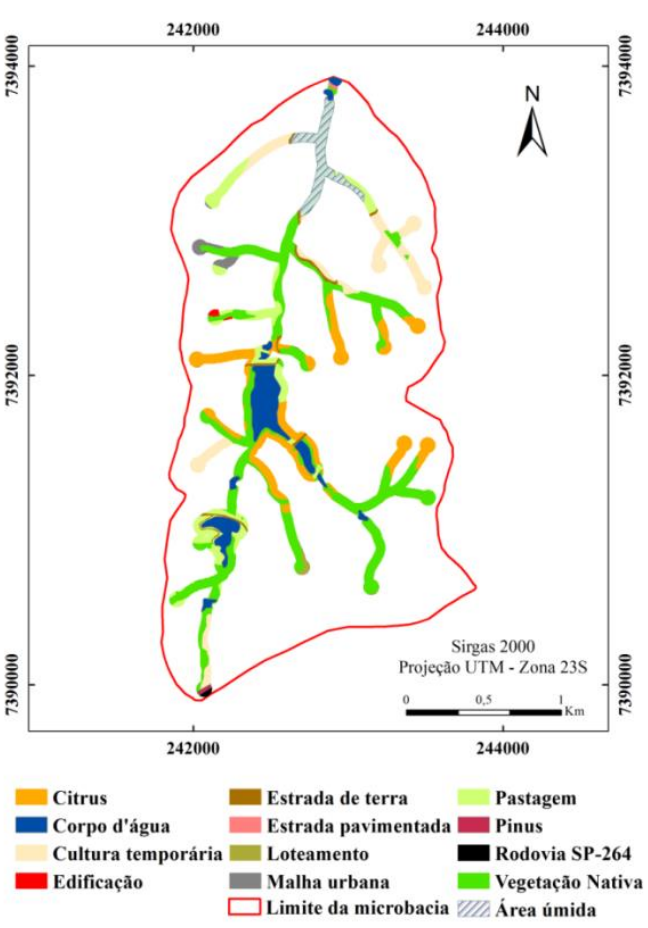

(b)

Figura 2. Uso e cobertura da terra na microbacia do Ipaneminha de Baixo, Sorocaba, SP (a) e da área de preservação permanente (b).

Figure 2. Use and land cover in the Ipaneminha de Baixo watershed, Sorocaba, SP (a) and the permanent preservation area (b).

Tabela 3. Área, em hectares, ocupada por cada categoria de uso e cobertura da terra da microbacia do Ipaneminha de Baixo, Sorocaba, SP e das áreas de preservação permanente (APP).

Table 3. Area, in hectares, occupied by each category of use and land cover of Ipaneminha de Baixo watershed, Sorocaba, SP and permanent preservation areas (APP).

\begin{tabular}{lrrrr}
\hline & \multicolumn{2}{c}{ Microbacia } & \multicolumn{1}{c}{ APP } \\
\hline Categorias e uso e cobertura da terra & Área (ha) & \multicolumn{1}{c}{$\%$} & \multicolumn{1}{c}{ Área (ha) } & \% \\
\hline Vegetação Nativa & 116,89 & 20,26 & 43,11 & 41,83 \\
Loteamento & 45,99 & 7,97 & 0,59 & 0,57 \\
Corpo d'água & 13,89 & 2,41 & 2,32 & 2,25 \\
Estrada de terra & 9,13 & 1,58 & 2,58 & 2,50 \\
Estrada pavimentada & 1,46 & 0,25 & 0,14 & 0,13 \\
Rodovia SP-264 & 8,11 & 1,40 & 0,24 & 0,23 \\
Citrus & 135,03 & 23,40 & 19,10 & 18,53 \\
Malha urbana & 15,59 & 2,70 & 1,57 & 1,52 \\
Área edificada & 5,18 & 0,89 & 0,29 & 0,28 \\
Pastagem & 107,76 & 18,68 & 12,99 & 12,60 \\
Cultura temporária & 98,04 & 17,00 & 13,03 & 12,64 \\
Área úmida & 19,14 & 3,33 & 6,91 & 6,71 \\
Pinus & 0,87 & 0,15 & 0,22 & 0,21 \\
\hline Total & 577,00 & 100 & 103,06 & 100 \\
\hline
\end{tabular}

\section{DISCUSSÃO}

\section{Morfometria}

Considera-se que, quanto mais ramificada for a rede, mais eficiente será o sistema de drenagem (TONELLO, et al., 2006).

A carga de sedimentos, a compartimentação litológica, a estruturação geológica e a declividade dos canais, segundo Horton (1945), influenciam a sinuosidade (Is). Quando o Is possui valor próximo a 1,0 os canais

FLORESTA, Curitiba, PR, v. 46, n. 4, p. 439 - 446, out. / dez. 2016.

Leal, M. S.; Tonello, K. C.

ISSN eletrônico 1982-4688

DOI: $10.5380 /$ rf.v46i3.45809 
apresentam tendência retilínea e tendem a ser tortuosos com valores superiores a 2,0; enquanto que os valores intermediários indicam formas transicionais (SCHUMM; LICHTY, 1963). O Is encontrado nesse estudo foi muito próximo a 1,0 apontando a tendência retilínea, o que pode implicar em maior velocidade da água, maior carreamento e menor acúmulo de sedimentos no canal principal (ANTONELLI; THOMAZ, 2007).

A forma de uma bacia hidrográfica está relacionada ao tempo de concentração, ou seja, tempo que a água do ponto mais remoto leva para chegar à foz da mesma. Quanto menor o valor do fator de forma mais alongada tende ser a bacia (LIMA, 2008). Segundo Villela e Mattos (1975), uma bacia com o fator de forma baixo, como o valor encontrado para a microbacia em estudo (Tabela 2), é menos sujeita a enchentes que outra de mesmo tamanho, porém com fator de forma distinto.

Com um coeficiente de compacidade próximo a 1,0 a bacia se aproxima de uma forma circular, caso contrário a forma da bacia é mais alongada (VILLELA; MATTOS, 1975). Neste caso, o resultado indica que a bacia se aproxima de uma forma mais alongada.

No caso do Ic também quanto mais próximo de 1,0 mais circular é a bacia (LIMA, 2008), assim o Ic encontrado corrobora com uma forma mais próxima da alongada e maior tempo de concentração da água.

$\mathrm{O}$ fato da microbacia ter sido classificada com formato oblongo/ovalado indica que a mesma tem uma tendência baixa/mediana a enchentes, em condições normais de pluviosidade anual. Em estudo semelhante realizado por Pinheiro (2011) na microbacia do córrego Ipaneminha, também afluente do Rio Ipanema, os valores dos índices relacionados à forma foram muito próximos aos deste estudo.

A declividade também está relacionada ao tempo de concentração da água na bacia, influenciando assim o tempo em que a água da chuva demora a alcançar a rede de drenagem. Quanto maior o tempo de concentração, devido a menor declividade do terreno, maior a chance de infiltração da água no solo, o que vai depender também do uso e cobertura da terra (LIMA, 2008). Pinheiro (2011) e Antoneli e Thomaz (2007) também encontraram valores de declividade média muito próximos ao encontrado nesta microbacia, 8,2\% e $8,0 \%$ respectivamente.

O baixo valor de razão de relevo obtido indica que o rio tem uma baixa razão entre o componente vertical (amplitude altimétrica) e horizontal (comprimento) e quanto menor o valor menos acidentado é o relevo predominante na região. Menezes et al. (2014) obtiveram o mesmo valor de razão de relevo para a bacia do Ribeirão Vermelho, MG.

$\mathrm{O}$ gradiente do canal principal expressa em porcentagem a relação entre a cota máxima e o comprimento do canal principal. A bacia do Arroio Boa Vista, PR analisada por Antoneli e Thomaz (2007) apresentou gradiente de $15 \%$, próximo ao do presente estudo.

Analisando esses dois últimos parâmetros percebe-se que o canal principal, assim como a bacia, apresenta baixa declividade o que proporciona um escoamento superficial mais lento e menor pressão de erosão.

Valores baixos de densidade de drenagem estão geralmente associados a regiões de solos mais permeáveis, possibilitando que a infiltração seja mais eficiente (LIMA, 2008). Valor semelhante foi encontrado por Silva e Tonello (2014) na bacia do Ribeirão dos Pinheirinhos em Brotas, SP. Pinheiro et al. (2011) ao estudar uma microbacia com valores aproximados de área e declividade média observou uma densidade de drenagem inferior $\left(1,86 \mathrm{~km} / \mathrm{km}^{2}\right)$.

O valor encontrado para a extensão do percurso superficial mostra que a microbacia possui grande distância de escoamento, o que acarreta em maior tempo de concentração da água, diminuindo assim a tendência de erosão já que a declividade também é baixa (NARDINI, 2013).

Após analisar os resultados encontrados (a forma oblonga/ovalada com tendência mediana a enchentes, o relevo caracterizado como ondulado e a baixa declividade apresentada pelo canal principal) percebeu-se que esses aspectos são positivos em termos de infiltração, já que quanto menor a declividade maior o tempo de concentração da água e maior a chance da água infiltrar no solo.

\section{Uso e cobertura da terra}

A baixa declividade do terreno favorece o cultivo de espécies agrícolas (CORSEUIL; CAMPOS, 2007), representadas nessa região por culturas temporárias e citrus, que juntas somaram quase $50 \%$ da microbacia, apontando uma tendência agrícola na área de estudo.

A vegetação nativa está representada por fragmentos dispersos na microbacia sendo que o maior fragmento pertence ao loteamento.

O loteamento em questão está localizado na região de cabeceira da microbacia e como o solo encontrase descoberto pode ocorrer processos erosivos e assoreamento das nascentes e corpos d'água.

As áreas de preservação permanente dos corpos d'água não estão sendo ocupadas somente por vegetação nativa, no entanto, de acordo com a Lei Federal $n^{\circ}$. 12.651/12 toda a área considerada de preservação permanente deve estar coberta por vegetação nativa, havendo, portanto, um déficit de vegetação, a qual deve ser restaurada. 
As áreas compostas por estradas, rodovia, malha urbana, edificações, loteamento podem apresentar infiltração de água no solo reduzida, em comparação às áreas ocupadas por vegetação, já que a cobertura vegetal diminui o escoamento superficial e favorece a infiltração da água no solo (BERTONI; LOMBARDI NETO, 1990).

Portanto é de fundamental importância o planejamento do uso e cobertura da terra baseado nas características locais para que a microbacia se comporte como uma área conservadora de solo e água, onde os usos e a cobertura da terra sejam compatíveis com sua aptidão e que práticas conservacionistas de solo sejam implantadas.

\section{CONCLUSÃO}

As análises permitiram concluir que:

- A microbacia apresentou características morfométricas favoráveis ao processo de infiltração da água no solo e se manejada de maneira correta é uma área importante para a conservação de água.

- As culturas temporárias e o citrus somaram cerca de $40 \%$ do uso total da microbacia, as pastagens e a vegetação nativa estavam presentes em aproximadamente $20 \%$ da área total, cada uma.

- Nas áreas de preservação permanente que não estavam cobertas por vegetação nativa, como indicado na legislação, é necessária portanto a restauração da vegetação nativa.

\section{AGRADECIMENTO}

Bolsa de financiamento CAPES.

\section{REFERÊNCIAS}

ANTONELI, V.; THOMAZ, E. L. Caracterização do meio físico da bacia do Arroio Boa Vista - GuamirangaPR. Caminhos da Geografia, Uberlândia, v. 8, n. 21, p. 46-58, 2007.

ARCOVA, F. C. S.; CESAR, S. F.; CICCO, V. Qualidade da água em microbacias recobertas por floresta de Mata Atlântica, Cunha, SP. Revista do Instituto Florestal, v. 10, n. 2, p. 185-196, 1998.

BERTONI, J.; LOMBARDI NETO, F. Conservação do solo. São Paulo: Ícone, 1990. 335 p.

BRASIL. Lei Federal n $n^{\circ}$. 9.433, de 08 de janeiro de 1997. Institui a Política Nacional de Recursos Hídricos, cria o Sistema Nacional de Gerenciamento de Recursos Hídricos, regulamenta o inciso XIX do art. 21 da Constituição Federal, e altera o art. $1^{\circ}$ da Lei no 8.001, de 13 de março de 1990, que modificou a Lei $n^{\circ} 7.990$, de 28 de dezembro de 1989. Diário Oficial da União, Brasília, DF, oito de janeiro de 1997. Disponível em: < http://www.planalto.gov.br/ccivil_03/leis/19433.htm>. Acesso em: 09 jun. 2015.

BRASIL. Lei Federal no $n^{\circ}$ 12.651, de 25 de maio de 2012, dispõe sobre a proteção da vegetação nativa; altera as Leis $\mathrm{n}^{\text {os }} 6.938$, de 31 de agosto de 1981, 9.393, de 19 de dezembro de 1996, e 11.428, de 22 de dezembro de 2006; revoga as Leis $\mathrm{n}^{\mathrm{os}} 4.771$, de 15 de setembro de 1965, e 7.754, de 14 de abril de 1989, e a Medida Provisória $\mathrm{n}^{\mathrm{o}}$ 2.166-67, de 24 de agosto de 2001; e dá outras providências. Diário Oficial da União, Brasília, DF, vinte e cinco de maio de 2012. Disponível em: http://www.planalto.gov.br/ccivil_03/_ato20112014/2012/lei/112651.htm. Acesso em: 23 abril 2015.

CENTRO DE PESQUISAS METEREOLÓGICAS E CLIMÁTICAS APLICADAS A AGRICULTURA (CEPAGRI). Disponível em: <http://www.cpa.unicamp.br/outras-informacoes/clima_muni_584.html>. Acesso em: 13 jan. 2015

CORSEUIL, C. W.; CAMPOS, C. Geoprocessamento aplicado na determinação das classes de declividade e uso de terras da microbacia do Arroio Ajuricaba - Marechal Cândido Rondom - PR. Engenharia Agrícola, v. 22, n. 1, p. 33-41, 2007.

EMPRESA BRASILEIRA DE PESQUISA AGROPECUÁRIA (EMBRAPA). Serviço Nacional de Levantamento e Conservação de Solos (Rio de Janeiro, RJ). In: Súmula da X reunião técnica de levantamento de solos, Rio de Janeiro, 1979. 83 p. (EMBRAPA-SNLCS. Micelânea, 1).

FREITAS, E. P.; MORAES, J. F. L.; PECHE FILHO, A.; STORINO, M. Indicadores ambientais para áreas de preservação permanente. Rev. bras. eng. agríc. ambient., Campina Grande, v. 17, n. 4, p. 443-449, 2013.

HORTON, R. E. Erosional development of streams and their drainage basins, hidrophysical approach to quantitative morphology. Geological Society of America Bulletin, v. 56, p. 275-370, 1945. 
HORTON, R. E. Drainage basin characteristics. Transactions-American Geophysical Union, v. 13, p. 350$361,1932$.

INSTITUTO BRASILEIRO DE GEOGRAFIA E ESTATÍSTICA (IBGE). Manual técnico de uso da terra. Rio de Janeiro: IBGE, $3^{\mathrm{a}}$. ed. 2013, 171 p.

Cidades. Disponível em: <http://www.cidades.ibge.gov.br/xtras/perfil.php?lang=\&codmun=355220>. Acesso em 28 jan. 2016.

INSTITUTO NACIONAL DE COLONIZAÇÃO E REFORMA AGRÁRIA (INCRA). Sistema Nacional de Cadastro Rural, 2013. Disponível em: <http://www.incra.gov.br/sites/default/files/uploads/estrutura-fundiaria/ regularizacao-fundiaria/indices-cadastrais/indices_basicos_2013_por_municipio.pdf >. Acesso em: 12 agosto 2016.

LIMA, W. P. Hidrologia Florestal aplicada ao Manejo de Bacias Hidrográficas. Piracicaba/SP: Escola Superior de Agricultura "Luiz de Queiróz”, 2008, 245 p.

LIMA, W. P.; ZAKIA, M. J. B. Hidrologia de matas ciliares. In: Rodrigues, R. R.; Leitão Filho, H. F. (ed.). Matas Ciliares: Conservação e recuperação. São Paulo: EDUSP, FAPESP, 2.ed. 2004, 320 p.

MENEZES, J. P. C.; FRANCO, C. S.; OLIVEIRA, L. F. C.; BITTENCOURT, R. P.; FARIAS, M. S.; FIA, R. Morfometria e evolução do uso do solo e da vazão de máxima em uma microbacia urbana. Revista Brasileira de Geomorfologia, v. 15, n. 4, p. 659-672, 2014.

MINISTÉRIO DO MEIO AMBIENTE (MMA) Geo Catálogo. Disponível em: <http://geocatalogo.ibama.gov.br/> . Acesso em: 15 maio 2015.

NARDINI, R. C.; POLLO, R. A.; BARROS, Z. X.; CARDOSO, L. G.; GOMES, L. N. Análise morfométrica e simulação das Áreas de Preservação Permanente de uma microbacia hidrográfica. Irriga, Botucatu, v. 18, n. 4, p. 687-699, 2013.

OLIVEIRA, J. B. de, CAMARGO, M. N.; ROSSI, M.; CALDERANO FILHO, B. Mapa Pedológico do Estado de São Paulo: legenda expandida. Campinas: Instituto Agronômico/EMBRAPA - Solos, 1999, 64 p.

PINHEIRO, R. C.; TONELLO, K. C.; VALENTE, R. O. A.; SANTOS, I. P. Ocupação e caracterização hidrológica da microbacia do Córrego Ipaneminha, Sorocaba-SP. Irriga, Botucatu, v. 16, n. 3, p. 234-245, 2011.

PINTO, L. V. A.; BOTELHO, S. A.; DAVIDE, A. C.; FERREIRA, E. Estudo das nascentes da bacia hidrográfica do Ribeirão Santa Cruz, Lavras, MG. SCIENTIA FORESTALIS, n. 65, p. 197-206, 2004.

SCHUMM, S. A. Evolution of drainage systems and slopes in badlands of Perth Amboy. Bulletin of Geological Society of America, n. 67, p. 597-646, 1956.

SCHUMM, S. A.; LICHTY, R. W. Channel widening and flood -plain construction along Cimarron River, southwestern Kansas. Geol. Soc. Am. Bull., v. 70, p. 16-75, 1963.

SILVA, J. L.; TONELLO, K. C. Morfometria da Bacia Hidrográfica do Ribeirão dos Pinheirinhos, Brotas/SP. Irriga, Botucatu, v. 19, n. 1, p. 103-114, 2014.

STRAHLER, A. N. Quantitative analysis of watershed geomorphology. Trans. American Geophysical Union, v. 38, p. 913-920, 1957.

STRAHLER, A. N. Quantitative geomorphology of drainage basins and channel networks. In: CHOW, V. T. (Ed.) Handbook of applied hydrology. New York, McGraw-Hill, 1964.

TONELlO, K. C.; DIAS, H. C. T.; SOUZA, A. L.; RIBEIRO, C. A. A. S.; LEITE, F. P. Morfometria da bacia hidrográfica da Cachoeira das Pombas, Guanhães - MG. Revista Árvore, Viçosa-MG, v. 4, n. 8, p. 156-168, 2006.

VILLELA, S. M.; MATTOS, A. Hidrologia aplicada. São Paulo: McGraw-Hill do Brasil, 1975, 245 p.

VILLELA, F. N. J. Análise da relação relevo-rocha-solo no contato Planalto Atlântico - Depressão Periférica Paulista. 2011. 279 f. Tese (Doutorado em Geografia Física). Faculdade de Filosofia, Letras e Ciências Humanas, Universidade de São Paulo, São Paulo, 2011. 